\title{
Distinct patterns in the gut microbiota after surgical or medical therapy in obese patients
}

\author{
Daniel A. Medina ${ }^{1}$, Juan P. Pedreros ${ }^{1}{ }^{2}$, Dannae Turiel ${ }^{2}$, Nicolas Quezada ${ }^{2,3}$, Fernando Pimentel $^{3}$, Alex \\ Escalona $^{4}$, Daniel Garrido ${ }^{\text {Corresp. } 1}$ \\ 1 Department of Chemical and Bioprocess Engineering, Pontificia Universidad Católica de Chile, Santiago, Santiago, Chile \\ 2 Department of Digestive Surgery, School of Medicine, Pontificia Universidad Católica de Chile, Santiago, Chile \\ 3 Departamento de Cirugia Digestiva, Escuela de Medicina, Pontificia Universidad Católica de Chile, Santiago, Chile \\ 4 Department of Surgery, Faculty of Medicine, Universidad de Los Andes, Santiago, Chile \\ Corresponding Author: Daniel Garrido \\ Email address: dgarridoc@ing.puc.cl
}

Bariatric surgery is highly successful in improving health compared to conventional dietary treatments. It has been suggested that the gut microbiota is a relevant factor in weight loss after bariatric surgery. Considering that bariatric procedures cause different rearrangements of the digestive tract, they probably have different effects on the gut microbiota. In this study, we compared the impact of medical treatment, sleeve gastrectomy and Roux-en-Y gastric bypass on the gut microbiota from obese subjects. Anthropometric and clinical parameters were registered before, 6 and 12 months after treatment. Fecal samples were collected and microbiota composition was studied before and 6 months post treatment using 16S rRNA gene sequencing and qPCR. In comparison to dietary treatment, changes in intestinal microbiota were more pronounced in patients subjected to surgery, observing a bloom in Proteobacteria. Interestingly, Bacteroidetes abundance was largely different after six months of each surgical procedure. Furthermore, changes in weight and $\mathrm{BMI}$, or glucose metabolism, correlated positively with changes in these two phyla in these surgical procedures. These results indicate that distinct surgical procedures alter the gut microbiota differently, and changes in gut microbiota might contribute to health improvement. This study contributes to our understanding of the impact of weight loss surgery on the gut microbiota, and could be used to replicate this effect using targeted therapies. 


\section{Distinct Patterns in the Gut Microbiota after Surgical or Medical Therapy in Obese Patients} 2

3 Daniel A. Medina ${ }^{1}$, Juan P. Pedreros ${ }^{1}$, Dannae Turiel$^{2}$, Nicolas Quezada ${ }^{2}$, Fernando Pimentel $^{2}$, 4 Alex Escalona ${ }^{3}$, Daniel Garrido ${ }^{1}$.

5

$6{ }^{1}$ Department of Chemical and Bioprocess Engineering, Pontificia Universidad Catolica Chile;

7 2Department of Digestive Surgery, School of Medicine, Pontificia Universidad Catolica Chile;

$8{ }^{3}$ Department of Surgery, Faculty of Medicine, Universidad de los Andes.

10 *Corresponding author: Daniel Garrido

11 Department of Chemical and Bioprocess Engineering

12 School of Engineering

13 Pontificia Universidad Catolica Chile

14 Vicuña Mackenna 4860

15 Santiago, Chile

16 Phone: 56-223541143

17 Email: dgarridoc@ing.puc.cl

19 Abstract

Bariatric surgery is highly successful in improving health compared to conventional dietary

21 treatments. It has been suggested that the gut microbiota is a relevant factor in weight loss after

22 bariatric surgery. Considering that bariatric procedures cause different rearrangements of the 23 digestive tract, they probably have different effects on the gut microbiota. In this study, we 24 compared the impact of medical treatment, sleeve gastrectomy and Roux-en-Y gastric bypass on 
25 the gut microbiota from obese subjects. Anthropometric and clinical parameters were registered

26 before, 6 and 12 months after treatment. Fecal samples were collected and microbiota composition

27 was studied before and 6 months post treatment using 16S rRNA gene sequencing and qPCR. In

28 comparison to dietary treatment, changes in intestinal microbiota were more pronounced in

29 patients subjected to surgery, observing a bloom in Proteobacteria. Other signature changes were

30 observed in the Bacteroidetes phylum. Furthermore, changes in certain clinical parameters

31 correlated with changes in some taxa. These results indicate that distinct surgical procedures alter

32 the gut microbiota differently, and these discrete changes correlate with metabolic markers. This

33 study contributes to our understanding of the impact of weight loss surgery on the gut microbiota,

34 and could be used to replicate this effect using targeted therapies.

36 Running title: Changes in gut microbiota after two bariatric surgeries

Introduction

Obesity is a worldwide health problem that negatively affects quality of life. According to 40 the World Health Organization, more than 1900 million people over 18 years old have a body mass 41 index (BMI) of $25 \mathrm{~kg} / \mathrm{m}^{2}$ or greater, and 600 million are catalogued as obese, with BMI $\geq 30 \mathrm{~kg} / \mathrm{m}^{2}$

42 (World Health Organization, 2016). Type 2 diabetes, cardiovascular disorders, certain cancers and asthma are comorbidities that show an increased risk in subjects with obesity.

The first line of treatment for obesity is medical treatment, which combines diet and physical activity. Unfortunately, the effectiveness of this approach appears to be only short term, since weight regain is common and not all patients respond similarly (Kral et al., 2012). In subjects with obesity and comorbidities, surgical procedures have been successful in controlling weight in 
48 the long term and reducing the incidence of related comorbidities such as hypertension and type 2

49 diabetes (Sjöström et al., 2007; Sjöström, 2008; Eldar et al., 2011). These procedures are

50 collectively known as bariatric surgery (BS). Indications for BS include a BMI more than 40 or a

51 BMI more than 35 with medical comorbidities (Mechanick et al., 2013). BS can either restrict food

52 intake (restrictive), or reduce nutrient absorption (malabsorptive) (Buchwald et al., 2004). Sleeve

53 gastrectomy (SG) is an example of a restrictive procedure. It removes a significant portion of the

54 stomach, decreasing its volume and leading to a significant reduction in the amount of food

55 consumed (Gumbs et al., 2007). While, Roux-en-Y gastric bypass (RYGB) is both restrictive and

56 malabsorptive, creating a small stomach pouch connected to the proximal jejunum, reducing

57 stomach volume to restrict food intake and bypassing food to the small intestine (Tice et al., 2008).

58 Both procedures cause anatomical rearrangements that directly change gastrointestinal anatomy 59 and function, accelerating food transit and altering hormonal regulation (Tice et al., 2008; Tran et

60 al., 2016). While weight loss could be more pronounced in patients undergoing RYGB compared

61 to SG after two years, the risk for post-surgical complications is greater in patients who have

62 undergone RYGB (Lager et al., 2016). Other studies indicate that RYGB significantly outperforms

63 SG in achieving glycated haemoglobin (HbA1C) values under 7.0\% without medications (Schauer

64 et al., 2014). In aggregate, these observations make interesting to understand the changes in the

65 gut microbiota associated to both surgeries.

66

67 considered a metabolic organ. It consists of a dense community of microorganisms that matches

68 the number of cells of the human body (Sender et al., 2016). The influence of the gut microbiota

69 is better exemplified at the metabolic level, since the microbiota synthesizes vitamins and amino

70 acids absorbed by the epithelium (LeBlanc et al., 2013). Additionally, it is capable of fermenting 
71 complex dietary polysaccharides and other dietary sources, resulting in the production of short

72 chain fatty acids (SCFA) such as acetate, propionate and butyrate (Cook and Sellin, 1998; Hijova

73 and Chmelarova, 2007; Morrison et al., 2016). These acids modulate physiological processes in

74 several tissues, such as insulin sensitivity, liver function and cholesterol metabolism (Todesco et

75 al., 1991; Demigné et al., 1995; Fushimi et al., 2006; Gao et al., 2009; den Besten et al., 2013).

76 Furthermore, the gut microbiota plays important roles in the development of the immune system

77 and the maintenance of intestinal epithelium integrity (Sekirov et al., 2010).

Certain studies have linked obesity with changes in the composition and metabolic function

79 of the gut microbiota (Bäckhed et al., 2004; Ley et al., 2005; Turnbaugh et al., 2006; Tremaroli et

al., 2015; Palleja et al., 2016). The gut microbiota is dominated by species that belong mainly to

the Firmicutes and Bacteroidetes phylum, and to a lesser degree to Actinobacteria, Proteobacteria

and Verrucomicrobia (Qin et al., 2010). In obese subjects, it has been observed a decrease in the

relative proportion of the Bacteroidetes/Firmicutes ratio, compared to lean people. Interestingly,

this phenotype is transmissible to mice. Moreover, this proportion appears increased after weight

loss on two low-calorie diets (Ley et al., 2006). These taxonomical differences in the gut microbiota of obese subjects might contribute to obesity in several ways, including energy extraction from the diet (Turnbaugh et al., 2006), mainly from SCFA, together with an increase in low-grade inflammation and altered bile acid metabolism (Khan et al., 2016).

Interestingly, bariatric surgery also induces important changes in the composition of the gut microbiota of patients undergoing these procedures (Zhang et al., 2009; Li et al., 2011; Kong

91 et al., 2013). The main changes reported after surgical intervention includes increases in Proteobacteria (E. coli, Enterobacter spp.), decreases in Clostridium and changes in Bacteroides and Prevotella (Zhang et al., 2009; Furet et al., 2010; Li et al., 2011; Huttenhower et al., 2012; 
94 Kong et al., 2013). Furthermore, it has been reported that these taxonomical and functional changes

95 in the microbiota are stable nine years after RYGB intervention (Tremaroli et al., 2015).

96 Whether the observed changes in microbiota composition contribute to weight loss or they

97 are just a consequence of the surgical procedure is unclear. In a mouse model, transfer of the gut

98 microbiota from RYGB-operated to germ-free mice induced weight loss and decreased fat mass

99 in comparison with germ-free animals colonized with microbiota from sham-operated animals

100 (Liou et al., 2013). This suggested that the gut microbiota is an active player in weight loss in

101 obesity surgery, and that weight loss is a transmissible trait of the microbiota post-surgery. On the

102 other hand, a recent report showed that in one person, fecal microbiota from a healthy but

103 overweight donor induced obesity (Alang \& Kelly, 2015).

104 Sleeve gastrectomy and gastric bypass are common bariatric procedures that exert different 105 physiological changes in the gastrointestinal tract, possibly inducing different changes in the gut

106 microbiota that may contribute to different health outcomes. Unfortunately, this has been studied 107 mostly using animal models and more evidence is needed to correlate changes in microbiota 108 compositions with health markers. To provide further information regarding the impact of bariatric

109 surgery treatments on the gut microbiota composition, in this work we compared the changes in

110 clinical parameters and microbiota composition in subjects undergoing medical dietary treatment

111 (MT), sleeve gastrectomy (SG) or Roux-en-Y gastric bypass (RYGB).

112

\section{Material and Methods}

114

\section{Patient inclusion and clinical parameters}


117 the Ethics Committee of the Faculty of Medicine, Pontificia Universidad Catolica de Chile. All

118 study participants provided written informed consent. Participants of this study were recruited

119 from eligible candidates of the Obesity Program from Red de Salud UC-Christus. Eligible subjects

120 were men or women, 18 to 60 years old with a body mass index (BMI) 30 to $50 \mathrm{~kg} / \mathrm{m} 2$. Women

121 who were pregnant or with the intention to get pregnant were excluded. Other exclusion criteria

122 include chronic antibiotic use, record of small intestine and/or colon resection, intestinal

123 inflammatory diseases and probiotic consumption. A total of 19 patients were recruited. Nine

124 patients following medical dietary treatment (MT), based in hypocaloric diet combined with

125 moderate physical activity three times per week, in addition to a monthly doctor visit for twelve

126 months. In addition, five recruited patients underwent Roux-en-Y gastric bypass (RYGB) and five

127 sleeve gastrectomy (SG), with a 5-trocar technique as described previously (Escalona et al., 2007;

128 Boza et al., 2012). Patients undergoing either RYBG or SG received nutrient supplementation

129 during the follow-up period such as multivitamin supplements, iron, vitamin B12 and calcium, and

130 were instructed to follow a hypocaloric diet.

131 Anthropometric and clinical parameters were obtained in a clinical assessment. The

132 patients were evaluated in three opportunities (baseline evaluation before medical intervertion, 6

133 and 12 months post treatment), which consisted of anthropometry measurements (weight and size),

134 laboratory studies taking blood sample (lipids, HOMA and HbA1c). Patients were instructed to

135 bring a homogenized fecal sample in a sterile container the day of the evaluation, which was

136 transported in ice and immediately stored at $-80{ }^{\circ} \mathrm{C}$.

137 Descriptive statistical parameters (mean and standard deviation), and significant

138 differences between clinical data were estimated by non-parametric unpaired Wilcoxon rank-sum 
139 test at 0.05 significance level. Mean differences between phylum changes were contrasted using

140 parametric unpaired t-test at 0.05 significance level. Pairwise Spearman Rank correlations between

141 clinical parameters changes and bacterial variation were done using $\mathrm{R}$ statistical environment ( $\mathrm{R}$

142 Core Team, 2013).

143

144 DNA isolation

145 Fecal samples were thawed and $150 \mathrm{mg}$ were used for total DNA isolation using the ZR

146 Fecal DNA MiniPrep kit (Zymo Research, USA) following manufacturer instructions and using a

147 Disruptor Genie device (Scientific Industries, USA). Total DNA concentration was measured in a

148 NanoDrop 2000c device (Thermo Fisher Scientific, USA).

149

150

Analysis of gut microbiota by $16 S$ rRNA gene sequencing

Fecal DNA samples were diluted to $20 \mathrm{ng} / \mu \mathrm{l}$ in Nuclease-free water (IDT, USA) and

152 submitted for Illumina MiSeq sequencing to Molecular Research DNA sequence services (MR-

153 DNA, USA). The $16 \mathrm{~S}$ rRNA gene V3 to V4 variable region was amplified using the $341 \mathrm{~F}$ and

154 785R primers (Klindworth et al., 2013), adding a barcode on the forward primer. The reaction was

155 performed in 30 cycles using the HotStarTaq Plus Master Mix Kit (Qiagen, USA). After

156 amplification, PCR products were checked in a 2\% agarose gel. Multiple samples were pooled

157 together and purified using calibrated Ampure XP beads (Agencourt Bioscience Corporation,

158 USA). The pooled and purified combined PCR products were used to prepare a DNA library using

159 TruSeq DNA LT Sample Prep Kit (Illumina, USA) following manufacturer instructions.

160 Sequencing was performed using MiSeq platform (Illumina, USA) by paired-end sequencing. 
162 analyze the 16S rRNA sequences (Caporaso et al., 2010; Navas-Molina et al., 2013). Briefly,

163 chimera sequences were removed, then paired sequences joined and barcode was depleted.

164 Operational taxonomic units (OTUs) were picked by closed reference command and defined by

165 clustering at $1 \%$ divergence (99\% similarity) using as reference the GreenGenes database

166 (DeSantis et al., 2006; McDonald et al., 2012) release 05-2013. Low sequence counts were filtered

167 from BIOM table using the minimum value of count/sample between all samples. To compare

168 phylum level changes, OTUs belonging to phyla with less than $1 \%$ representation were removed.

169 Alpha and Beta diversity were calculated using QIIME. BIOM OTU table and weighted Unifrac

170 tables were exported from QIIME to R environment (R Core Team, 2013) for statistical analysis

171 and figure representation. The raw data reads obtained from the MiSeq platform were stored in

172 SRA NCBI online public database with accession number SRP076859

173 (http://www.ncbi.nlm.nih.gov/sra/SRP076859).

174

175 qPCR amplification

176 In order to validate $16 \mathrm{~S}$ rRNA gene sequencing results, quantitative PCR analysis was

177 performed in fecal DNA samples using specific primers (Supplementary Table 1) that were

178 previously described (Rinttilä et al., 2004; Fierer \& Jackson, 2005; Frank et al., 2007; Bacchetti

179 De Gregoris et al., 2011). Amplification and detection were carried out in a StepOnePlus

180 equipment (Applied Biosystems, USA), using 96-well optical plates MicroAmp Fast Optical

181 (ThermoFisher, USA), filled with a mixture containing for each well $5 \mu$ l of PowerUp SYBR

182 Master Mix or Fast SYBR Green Master Mix (Applied Biosystems, USA), $0.3 \mu \mathrm{M}$ of each primer

$183(0.3 \mu \mathrm{l}$ each), $4.4 \mu \mathrm{l}$ nuclease-free water (IDT, USA) and $1 \mu \mathrm{l}$ of DNA previously diluted to 10 
$184 \mathrm{ng} / \mu \mathrm{l}$. DNA samples were amplified with an initial hold of $50^{\circ} \mathrm{C}$ for $2 \mathrm{~min}$ and a polymerase 185 activation step of $95{ }^{\circ} \mathrm{C}$ for 2 min for PowerUp SYBR Master Mix, or $95{ }^{\circ} \mathrm{C}$ for $20 \mathrm{~s}$ for Fast

186 SYBR Green Master Mix, followed by 40 cycles of a denaturation at $95{ }^{\circ} \mathrm{C}$ for $3 \mathrm{~s}$ and $62{ }^{\circ} \mathrm{C}$ for $18730 \mathrm{~s}$ annealing and elongation. To verify a single amplification peak, a melting curve was 188 performed by incrementing the temperature from $62^{\circ} \mathrm{C}$ to $95^{\circ} \mathrm{C}$. All the samples were amplified 189 in triplicate, and to correct primer efficiency, each plate contained a standard curve with ten-fold 190 dilutions of genomic DNA of one species of the corresponding phylum, starting from $10 \mathrm{ng}$ of 191 DNA of the following microorganisms. Firmicutes: Lactobacillus acidophilus ATCC 4356; 192 Bacteroides: B. dorei CL03T12C01, HM-718; NIAID, NIH; Actinobacteria: Bifidobacterium 193 longum subsp. infantis ATCC 15697; Proteobacteria: Escherichia coli K12. The 16S rRNA gene 194 copy number for each phylum in each sample was estimated from the corresponding standard 195 curve and adjusted by the average genome 16S rRNA gene copy number of bacteria. To convert 196 bacterial DNA amounts into copy number, the following equation was applied:

$$
\text { Copy number } 16 \text { S rRNA gene }=\frac{\text { Avogadro } N^{\circ}\left(\text { mol }^{-1}\right) * D N A \text { quantity }(g) * \text { Genome } 16 S \text { copy number }}{\text { Genome }(p b) * 660\left(\frac{g}{m o l}\right)}
$$

\section{Results}

\section{Effect of obesity treatments on clinical parameters}

In this study we compared the impact of three treatments for obesity on the gut microbiota, treatment. 
Six months after surgery, both RYGB and SG patients showed a marked weight loss, 207 accompanied by significantly lower BMI values (28\% and $29 \%$ decrease) and significant waist and hip perimeter reduction (Table $1 \&$ Supplementary Table 2). In contrast, patients on MT 209 showed similar weight after six months of treatment with no major improvements in their anthropometric parameters $(2.8 \%$ reduction in $\mathrm{BMI})$.

212 RYGB and SG treatments, we observed a decrease in insulin levels and glycemia, however these

213 levels maintained in a normal range. Importantly, surgery led to a significant improvement in 214 insulin sensitivity $($ HOMA < 3) after treatment. No statistical significant changes were observed 215 in lipid metabolism markers, nevertheless cholesterol and triglycerides tended to decrease in 216 RYGB after surgery (Supplementary Table 2). In contrast to the above observations, none of these 217 clinical parameters improved in MT patients. The general clinical observations presented here 218 appeared stable after 12 months of treatment (Supplementary Table 2).

\section{Obesity treatments induce global microbiota changes}

Next, we determined the composition of the gut microbiota of these patients before and six months after each treatment. The hypervariable regions V3-V4 of the 16S rRNA gene in each fecal DNA sample was amplified by PCR and the products were sequenced by MiSeq Illumina platform. We obtained over 2 million reads in 38 samples, which includes DNA from before and after 6 months of obesity treatment. Rarefaction curves of the number of OTUs at different sequencing depths were obtained for each DNA sample (Figure 1A), and they indicated saturation near 25,000 sequences. To evaluate microbiota composition of each patient, beta diversity was calculated, 
229 composition. Weighted Unifrac metric indicated that microbiota composition of MT patients was

230 similar between 0 and 6 months (Figure 1B). In contrast, the microbiota of patients undergoing

231 RYGB cluster together at the beginning of the study, but after treatment its composition was

232 divergent (Figure 1C). Conversely, microbiota composition in SG group was divergent before the 233 medical intervention but after treatment the compositions of 3 patients clustered closely (Figure 234 1D).

235 On average, more than $99 \%$ of sequences aligned to the phyla Firmicutes, Bacteroidetes, 236 Actinobacteria and Proteobacteria, with the first two being dominant in these samples (Figure 237 2A). Changes in the representation of each phylum in patients in each treatment were then 238 expressed as the ratio of the relative abundance after the intervention compared to pre-treatment 239 (Figure 2B, Figure 2C and Figure 2D). In MT patients, no major changes were observed in any of 240 these bacterial groups after six months, consistent with their poor response to the treatment. In 241 contrast, important changes were observed in RYGB and SG patients. In the RYGB group, both 242 Bacteroidetes and Proteobacteria increased in abundance (Figure 2D), while in SG patients we 243 observed an increase in Proteobacteria, but a decrease in Bacteroidetes (Figure 2C). Firmicutes 244 abundance was mostly unaffected in these patients. These different changes in microbiota also 245 caused an increase in the Bacteroides/Firmicutes ratio in SG patients (Figure 2E), and conversely 246 a strong decrease in the RYGB group, consistent with previous reports (Li et al., 2011; Kong et 247 al., 2013; Walters, Xu \& Knight, 2014). Abundance and microbial composition obtained from 16S 248 rRNA gene sequencing at genus-species level is summarized in Supplementary Table 3 for each 249 group.

In order to address to validate the 16S RNA gene sequencing results, the composition of 251 the microbiota of these patients was also evaluated by qPCR, quantifying the abundance of the 
252 phyla Actinobacteria, Firmicutes and Bacteroides, and the order Enterobacteriales. These results

253 showed a good correlation with data obtained by MiSeq. MT patients did not show major

254 microbiota changes after six months of treatment (Figure 3A). In RYGB patients, we observed an

255 increase in Bacteroidetes and a decrease in Firmicutes abundance (Figure 3B). Actinobacteria also

256 appeared in higher amounts in these patients. In contrast, in SG patients the abundance of

257 Bacteroidetes decreased, while the Firmicutes and Enterobacteriales proportions increased. This

258 in turn caused a reduction in the ratio Bacteroidetes/Firmicutes (Figure 3D), similar to our previous

259 observations by $16 \mathrm{~S}$ rRNA gene sequencing (Figure 2D). qPCR raw data and gene copy number

260 for each group are included in Supplementary Table 4, while phylum relative abundance measured

261 by qPCR and $16 \mathrm{~S}$ rRNA sequencing is presented in Supplementary Table 5.

262 A correlation analysis comparing the abundance of each microbiota across all patients is

263 represented in Figure 4. This analysis shows that in general the initial microbiota abundance of

264 most patients was uniformly correlated (R Spearman $>7$ ). However, after six months of each

265 treatment, microbiota abundance of RYGB subjects was very heterogeneous, in contrast to MT

266 and SG subjects which grouped according to their respective treatment (Figure 4B).

267 Microbial signatures for each obesity treatment

268 The most abundant genera or species that displayed the highest change in abundance after

269 each obesity treatment (determined by $16 \mathrm{~S}$ rRNA sequencing) is shown in Table 2 . These bacteria

270 mostly belong to the Firmicutes phylum. Changes in the microbiota of MT patients were less

271 pronounced compared to the surgical treatments. In the RYGB group, Succiniclastum sp. displayed

272 a significant increase, as well as a few Bacteroides and Citrobacter species (Table 2). A Bulleidia

273 OTU displayed the highest fold change in the SG group, followed by Escherichia coli and

274 Akkermansia muciniphila OTUs. Other interesting signatures observed include an increase of 
275 Streptococcus luteciae in both RYGB and SG patients. Species such as Bacteroides eggerthii,

276 Bacteroides coprophilus and Lactobacillales sp. showed an important increase in RYGB subjects,

277 but a marked down-representation after six months in the SG group.

278

279

\section{Associations between microbiota changes and clinical markers}

Finally, we evaluated whether changes in microbiota composition in each group correlated 281 with clinical and anthropometric data collected. Certain positive and negative associations between microbial changes and clinical markers after 6 months of each treatment were found, using Pairwise Spearman Rank correlation analysis (Figure 5). Only a few of them were statistically significant ( $p$-value $<0.05$ ). In MT patients, no significant correlations were observed. Changes in Proteobacteria positively correlated with weight loss and bilirubin levels in RYGB patients. In addition, a negative association between Actinobacteria and liver markers such as Gammaglutamyl transpeptidase and alkaline phosphatase was obtained. In the SG group, hip and waist perimeter reduction correlated negatively with Proteobacteria and Actinobacteria, and positively with Firmicutes abundance. In this group most significant clinical changes were associated with the reduction in Bacteroidetes, such as liver markers and $\mathrm{HbAlc}$.

\section{Discussion}

293

In this study we compared the impact of three different obesity treatments on the gut 295 microbiota and we investigated how these changes correlated with clinical markers. BS procedures are well known for causing a marked weight loss, and importantly reducing the incidence of comorbidities such as type 2 diabetes (Sjöström et al., 2007; Sjöström, 2008; Eldar et al., 2011). 
298 A direct contribution of the gut microbiota post-surgery in weight loss and reduced adiposity has

299 been shown in animal models (Liou et al., 2013). Moreover, the impact of these surgeries on the

300 microbiota have been shown to be stable in the long-term (Tremaroli et al., 2015).

301 The size of the study was relatively small, which might limit certain observations.

302 However, other similar studies have been conducted in small cohorts (Zhang et al., 2009; Graessler

303 et al., 2013; Damms-Machado et al., 2015; Tremaroli et al., 2015; Palleja et al., 2016), and changes

304 in the gut microbiota of these subjects are clear.

305 Both RYGB and SG induce different rearrangements in the gastrointestinal tract, and

306 therefore it is expected that they also cause changes in the gut microbiota composition. Most

307 studies to date have focused on the impact of RYGB procedures on the gut microbiota, and little

308 research has been done on SG. Previous clinical studies have shown clear alterations in the

309 microbiota associated to these treatments, especially in Proteobacteria (such as E. coli) (Zhang et

310 al., 2009; Furet et al., 2010; Kong et al., 2013; Tremaroli et al., 2015; Palleja et al., 2016). Evidence

311 in animal models indicate a similar pattern of microbiota alteration (Liou et al., 2013; Shao et al.,

312 2016). In concordance with previous studies, an important increase in Proteobacteria in RYGB

313 and SG was observed in this study. The overgrowth of these microbes could be associated with

314 increases in luminal acidity and dissolved oxygen after these procedures, conditions that largely

315 favour the growth of enterobacteria (Duncan et al., 2009). It could also be that Escherichia

316 contributes to a more efficient energy harvest after BS during the initial nutritional starvation

317 (Tennant et al., 1968).

318 In addition, we observed that the phylum Bacteroidetes was increased in RYGB patients,

319 however it was down-represented in SG subjects. The physiological changes associated with these

320 treatments, and their consequences may explain these differences, as Bacteroides species are 
321 dominant in the adult microbiome, and are well known for their foraging ability for complex

322 polysaccharides. Furthermore, these species are also favoured by less acidic luminal $\mathrm{pH}$ (Duncan

323 et al., 2009).

324 Previous studies regarding changes in microbiota associated to BS have also shown

325 changes in key microorganisms of the microbiome. For example, Akkermansia muciniphila has a

326 remarkable mucin degrading ability, and it has been shown to prevent inflammation and adipose

327 tissue alterations (Schneeberger et al., 2015). Mouse and clinical data have shown an increase in

328 the abundance of this species after RYGB (Liou et al., 2013; Palleja et al., 2016), and here we

329 observed a similar trend on SG patients. Faecalibacterium prausnitzii, a key species in the gut

330 microbiome (Miquel et al., 2015), appeared under-represented post RYGB (Palleja et al., 2016).

331 Sequencing data in this study also revealed other signature species with interesting changes.

332 Streptococcus luteciae (Firmicutes), increased its abundance means several fold in RYGB and SG,

333 but decrease in MT. A Lactobacillales OTU, Bacteroides coprophilus and Bacteroides eggerthii

334 were increased after RYGB but underrepresented post SG surgery. Conversely, a Bulleidia OTU

335 (Firmicutes) showed the highest increase after SG but reduced its abundance several fold post

336 RYGB. It is possible that the enrichment or depletion of these microorganisms in the gut

337 microbiota might contribute to the positive health outcomes of RYGB and SG.

338 Is important to take into consideration that fecal microbiota is more representative of the

339 large intestine, and evaluating the changes in upper parts of the intestine is difficult to achieve

340 (Goodrich et al., 2014). Moreover, gut microbiota composition is influenced by geography

341 distribution (De Filippo et al., 2010; Yatsunenko et al., 2012). Dietary and caloric restriction might

342 also have a direct impact in the gut microbiota after obesity surgery (Buchwald et al., 2004).

343 However, in this study we observed that medical treatment, consisting of an intervention with a 
344 low calorie diet and physical activity, does not result in significant changes in the gut microbiota 345 or weight markers.

346 Finally, we found certain significant associations between changes in bacterial phyla 347 abundance and clinical parameters after surgery. For example, changes in Proteobacteria 348 correlated negatively with weight and BMI in RYGB patients, and in SG patients we observed that

349 Bacteroidetes correlated with certain blood and hepatic markers. It would be interesting to 350 determine if these associations in humans are causative or are a consequence of each surgical 351 procedure. Unfortunately, this study is correlational, and therefore further functional studies are 352 needed to understand the role of the gut microbiota in weight loss and metabolic improvements 353 observed after bariatric surgery, as observed in animals (Liou et al. 2013; Tremaroli et al. 2015).

354 At least in mice, two studies have shown that the microbiota post-RYGB is capable of transmitting 355 the weight loss and reduced adiposity to germ-free mice, indicating a causal relationship of the 356 microbiota influencing metabolic processes (Liou et al. 2013; Tremaroli et al. 2015). In humans, 357 a recent report showed that fecal microbiota transplantation from a healthy but overweight donor 358 induced obesity in one person (Alang \& Kelly, 2015).

359 It is probable that advances in functional metagenomics, and measuring additional clinical 360 markers such as bile salts and hormone production, could provide a better description of the role 361 of the gut microbiota in health in the context of bariatric surgery. Also including larger cohorts, 362 evaluated for longer periods, might provide more solid answers. These studies will definitively 363 help to improve surgical procedures, and eventually design microbiome based bacto-therapies 364 aimed to treat metabolic disorders.

\section{Conclusions}



on the gut microbiota, including a comparison with the effect of medical treatment on human

369 subjects. While no major changes were observed on weight, clinical markers or the microbiota of

370 subjects on MT, both RYGB and SG caused major adjustments in the gut microbiota, which

371 correlated with certain anthropometric or metabolic parameters. An increase in Proteobacteria

372 was observed six months after both RYGB and SG, whereas Bacteroidetes increased in RYGB but

373 decreased in SG. These alterations are probably caused by the physiological rearrangements of the 374 gastrointestinal tract, and may in fact contribute to weight and metabolic improvement in these 375 subjects.

377 Bibliography

378 Alang N., Kelly CR. 2015. Weight Gain After Fecal Microbiota Transplantation. Open Forum 379 Infectious Diseases 2:ofv004-ofv004. DOI: 10.1093/ofid/ofv004.

380 Bacchetti De Gregoris T., Aldred N., Clare AS., Burgess JG. 2011. Improvement of phylum- and 381 class-specific primers for real-time PCR quantification of bacterial taxa. Journal of 382 Microbiological Methods 86:351-356. DOI: 10.1016/j.mimet.2011.06.010.

383 Bäckhed F., Ding H., Wang T., Hooper L V., Koh GY., Nagy A., Semenkovich CF., Gordon JI. 384 2004. The gut microbiota as an environmental factor that regulates fat storage. Proceedings 385 of the National Academy of Sciences of the United States of America 101:15718-23. DOI: $386 \quad 10.1073 /$ pnas. 0407076101.

387 den Besten G., van Eunen K., Groen AK., Venema K., Reijngoud D-J., Bakker BM. 2013. The 388 role of short-chain fatty acids in the interplay between diet, gut microbiota, and host energy 389 metabolism. Journal of Lipid Research 54:2325-2340. DOI: 10.1194/jlr.R036012. 
390 Boza C., Salinas J., Salgado N., Pérez G., Raddatz A., Funke R., Pimentel F., Ibáñez L. 2012.

391 Laparoscopic sleeve gastrectomy as a stand-alone procedure for morbid obesity: Report of

3921,000 cases and 3-year follow-up. Obesity Surgery 22:866-871. DOI: 10.1007/s11695-012$393 \quad 0591-6$.

394 Buchwald H., Avidor Y., Braunwald E., Jensen MD., Pories W., Fahrbach K., Shoelles K. 2004.

395 Bariatric surgery. A Systematic Review and Meta-analysis. JAMA : the journal of the 396 American Medical Association 292:1724-1737. DOI: 10.1016/j.mpsur.2008.09.006.

397 Caporaso JG., Kuczynski J., Stombaugh J., Bittinger K., Bushman FD., Costello EK., Fierer N., 398 Peña AG., Goodrich JK., Gordon JI., Huttley GA., Kelley ST., Knights D., Koenig JE., Ley

399 RE., Lozupone CA., McDonald D., Muegge BD., Pirrung M., Reeder J., Sevinsky JR., 400 Turnbaugh PJ., Walters WA., Widmann J., Yatsunenko T., Zaneveld J., Knight R. 2010. 401 QIIME allows analysis of high-throughput community sequencing data. Nature methods 402 7:335-6. DOI: 10.1038/nmeth.f.303.

403 Cook SI., Sellin JH. 1998. Review article: short chain fatty acids in health and disease.

404 Alimentary pharmacology \& therapeutics 12:499-507. DOI: 10.1046/j.1365$405 \quad 2036.1998 .00337 . x$.

406 Cummings JH., Ccu O. 1981. Short chain fatty acids in the human colon. Gut 22:763-779. DOI: $407 \quad$ 10.1136/gut.22.9.763.

408 Damms-Machado A., Mitra S., Schollenberger AE., Kramer KM., Meile T., K??nigsrainer A., 409 Huson DH., Bischoff SC. 2015. Effects of surgical and dietary weight loss therapy for 410 obesity on gut microbiota composition and nutrient absorption. BioMed Research 411 International 2015. DOI: 10.1155/2015/806248.

412 Demigné C., Morand C., Levrat M-A., Besson C., Moundras C., Rémésy C. 1995. Effect of 
413 Propionate on Fatty Acid and Cholesterol Synthesis and on Acetate Metabolism in Isolated

414 Rat Hepatocytes. The British Journal of Nutrition 74:209-219. DOI:

415 10.1079/BJN19950124.

416 DeSantis TZ., Hugenholtz P., Larsen N., Rojas M., Brodie EL., Keller K., Huber T., Dalevi D., 417 Hu P., Andersen GL. 2006. Greengenes, a chimera-checked 16S rRNA gene database and 418 workbench compatible with ARB. Applied and Environmental Microbiology 72:5069-5072. 419 DOI: $10.1128 /$ AEM.03006-05.

Duncan SH., Louis P., Thomson JM., Flint HJ. 2009. The role of pH in determining the species composition of the human colonic microbiota. Environ Microbiol 11:2112-2122. DOI: 10.1111/j.1462-2920.2009.01931.x.

423

424 425 426

Eldar S., Heneghan HM., Brethauer S a., Schauer PR. 2011. Bariatric surgery for treatment of obesity. International journal of obesity (2005) 35 Suppl 3:S16-21. DOI:

$$
\text { 10.1038/ijo.2011.142. }
$$

Escalona A., Devaud N., Pérez G., Crovari F., Boza C., Viviani P., Ibáñez L., Guzmán S. 2007. Antecolic versus retrocolic alimentary limb in laparoscopic Roux-en-Y gastric bypass: a comparative study. Surgery for Obesity and Related Diseases 3:423-427. DOI: 10.1016/j.soard.2007.04.005.

Fierer N., Jackson J. 2005. Assessment of soil microbial community structure by use of taxonspecific quantitative PCR assays. Applied and Environmental Microbiology 71:4117. DOI: 10.1128/AEM.71.7.4117.

De Filippo C., Cavalieri D., Di Paola M., Ramazzotti M., Poullet JB., Massart S., Collini S., Pieraccini G., Lionetti P. 2010. Impact of diet in shaping gut microbiota revealed by a comparative study in children from Europe and rural Africa. Proceedings of the National 
Academy of Sciences of the United States of America 107:14691-6. DOI: 10.1073/pnas. 1005963107.

Frank DN., St Amand AL., Feldman RA., Boedeker EC., Harpaz N., Pace NR. 2007. Molecularphylogenetic characterization of microbial community imbalances in human inflammatory bowel diseases. Proceedings of the National Academy of Sciences of the United States of America 104:13780-5. DOI: 10.1073/pnas.0706625104.

Furet J., Kong L., Tap J., Poitou C., Basdevant A., Bouillot J., Mariat D., Henegar C., Rizkalla S., Cle K. 2010. Differential Adaptation of Human Gut Microbiota to bariatric surgeryinduced weight loss. Diabetes 59:3049-3057. DOI: 10.2337/db10-0253.

Fushimi T., Suruga K., Oshima Y., Fukiharu M., Tsukamoto Y., Goda T. 2006. Dietary acetic acid reduces serum cholesterol and triacylglycerols in rats fed a cholesterol-rich diet. The British journal of nutrition 95:916-924. DOI: 10.1079/BJN20061740.

Gao Z., Yin J., Zhang J., Ward RE., Martin RJ., Lefevre M., Cefalu WT., Ye J. 2009. Butyrate improves insulin sensitivity and increases energy expenditure in mice. Diabetes 58:15091517. DOI: $10.2337 / \mathrm{db} 08-1637$.

Gill RS., Majumdar SR., Rueda-Clausen CF., Apte S., Birch DW., Karmali S., Sharma AM., Klarenbach S., Padwal RS. 2016. Comparative effectiveness and safety of gastric bypass, sleeve gastrectomy and adjustable gastric banding in a population-based bariatric program: prospective cohort study. Canadian journal of surgery. Journal canadien de chirurgie 59:13315. DOI: 10.1503/cjs.013315.

Goodrich JK., Waters JL., Poole AC., Sutter JL., Koren O., Blekhman R., Beaumont M., Van Treuren W., Knight R., Bell JT., Spector TD., Clark AG., Ley RE. 2014. Human genetics shape the gut microbiome. Cell 159:789-799. DOI: 10.1016/j.cell.2014.09.053. 
459 Graessler J., Qin Y., Zhong H., Zhang J., Licinio J., Wong M-L., Xu A., Chavakis T., Bornstein 460 a B., Ehrhart-Bornstein M., Lamounier-Zepter V., Lohmann T., Wolf T., Bornstein SR.

461 2013. Metagenomic sequencing of the human gut microbiome before and after bariatric 462 surgery in obese patients with type 2 diabetes: correlation with inflammatory and metabolic 463 parameters. The Pharmacogenomics Journal:514-522. DOI: 10.1038/tpj.2012.43.

464 Gumbs AA., Gagner M., Dakin G., Pomp A. 2007. Sleeve gastrectomy for morbid obesity. Obesity Surgery 17:962-969. DOI: 10.1007/s11695-007-9151-x.

Hijova E., Chmelarova A. 2007. Short chain fatty acids and colonic health. Bratislavsk?? lek??rske listy 108:354-358. DOI: 10.1111/j.1365-2982.2011.01744.x. Earl AM., FitzGerald MG., Fulton RS., Giglio MG., Hallsworth-Pepin K., Lobos EA., Madupu R., Magrini V., Martin JC., Mitreva M., Muzny DM., Sodergren EJ., Versalovic J., Wollam AM., Worley KC., Wortman JR., Young SK., Zeng Q., Aagaard KM., Abolude OO., Allen-Vercoe E., Alm EJ., Alvarado L., Andersen GL., Anderson S., Appelbaum E., Arachchi HM., Armitage G., Arze CA., Ayvaz T., Baker CC., Begg L., Belachew T., Bhonagiri V., Bihan M., Blaser MJ., Bloom T., Bonazzi V., Paul Brooks J., Buck GA., Buhay CJ., Busam DA., Campbell JL., Canon SR., Cantarel BL., Chain PSG., Chen I-MA., Chen L., Chhibba S., Chu K., Ciulla DM., Clemente JC., Clifton SW., Conlan S., Crabtree J., Cutting MA., Davidovics NJ., Davis CC., DeSantis TZ., Deal C., Delehaunty KD., 481 Dewhirst FE., Deych E., Ding Y., Dooling DJ., Dugan SP., Michael Dunne W., Scott Durkin A., Edgar RC., Erlich RL., Farmer CN., Farrell RM., Faust K., Feldgarden M., Felix VM., Fisher S., Fodor AA., Forney LJ., Foster L., Di Francesco V., Friedman J., Friedrich DC., Fronick CC., Fulton LL., Gao H., Garcia N., Giannoukos G., Giblin C., Giovanni 
MY., Goldberg JM., Goll J., Gonzalez A., Griggs A., Gujja S., Kinder Haake S., Haas BJ., Hamilton HA., Harris EL., Hepburn TA., Herter B., Hoffmann DE., Holder ME., Howarth C., Huang KH., Huse SM., Izard J., Jansson JK., Jiang H., Jordan C., Joshi V., Katancik JA., Keitel WA., Kelley ST., Kells C., King NB., Knights D., Kong HH., Koren O., Koren S., Kota KC., Kovar CL., Kyrpides NC., La Rosa PS., Lee SL., Lemon KP., Lennon N., Lewis CM., Lewis L., Ley RE., Li K., Liolios K., Liu B., Liu Y., Lo C-C., Lozupone CA., Dwayne Lunsford R., Madden T., Mahurkar AA., Mannon PJ., Mardis ER., Markowitz VM., Mavromatis K., McCorrison JM., McDonald D., McEwen J., McGuire AL., McInnes P., Mehta T., Mihindukulasuriya KA., Miller JR., Minx PJ., Newsham I., Nusbaum C., O’Laughlin M., Orvis J., Pagani I., Palaniappan K., Patel SM., Pearson M., Peterson J., Podar M., Pohl C., Pollard KS., Pop M., Priest ME., Proctor LM., Qin X., Raes J., Ravel J., Reid JG., Rho M., Rhodes R., Riehle KP., Rivera MC., Rodriguez-Mueller B., Rogers YH., Ross MC., Russ C., Sanka RK., Sankar P., Fah Sathirapongsasuti J., Schloss JA., Schloss PD., Schmidt TM., Scholz M., Schriml L., Schubert AM., Segata N., Segre JA., Shannon WD., Sharp RR., Sharpton TJ., Shenoy N., Sheth NU., Simone GA., Singh I., Smillie CS., Sobel JD., Sommer DD., Spicer P., Sutton GG., Sykes SM., Tabbaa DG., Thiagarajan M., Tomlinson CM., Torralba M., Treangen TJ., Truty RM., Vishnivetskaya TA., Walker J., Wang L., Wang Z., Ward D V., Warren W., Watson MA., Wellington C., Wetterstrand KA., White JR., Wilczek-Boney K., Wu Y., Wylie KM., Wylie T., Yandava C., Ye L., Ye Y., Yooseph S., Youmans BP., Zhang L., Zhou Y., Zhu Y., Zoloth L., Zucker JD., Birren BW., Gibbs RA., Highlander SK., Methé BA., Nelson KE., Petrosino JF., Weinstock GM., Wilson RK., White O. 2012. Structure, function and diversity of the healthy human microbiome. Nature 486:207-214. DOI: 10.1038/nature11234. 
505 Khan MJ., Gerasimidis K., Edwards CA., Shaikh MG. 2016. Role of Gut Microbiota in the 506 Aetiology of Obesity: Proposed Mechanisms and Review of the Literature. Journal of 507 Obesity 2016:1-27. DOI: 10.1155/2016/7353642.

508 Klindworth A., Pruesse E., Schweer T., Peplies J., Quast C., Horn M., Gl??ckner FO. 2013.

509 Evaluation of general 16S ribosomal RNA gene PCR primers for classical and next510 generation sequencing-based diversity studies. Nucleic Acids Research 41:1-11. DOI:

$511 \quad$ 10.1093/nar/gks808.

512 Kong L-C., Veronique Pelloux Basdevant AJA-W., Bouillot., Tap J-L., Zucker J., Jean-Daniel.,

513 Karine Cle'ment JD. 2013. Gut microbiota after gastric bypass in human obesity: $\mid$ rincreased

514 richness and associations of bacterial genera\rwith adipose tissue genes. American Society

515 for Nutrition 98:16-24. DOI: 10.3945/ajcn.113.058743.Obesity.

516 Kral JG., Kava RA., Catalano PM., Moore BJ. 2012. Severe obesity: The neglected epidemic.

517 Obesity Facts 5:254-269. DOI: 10.1159/000338566.

518 Lager CJ., Esfandiari NH., Subauste AR., Kraftson AT., Brown MB., Cassidy RB., Nay CK.,

519 Lockwood AL., Varban OA., Oral EA. 2016. Roux-En-Y Gastric Bypass Vs. Sleeve

520 Gastrectomy: Balancing the Risks of Surgery with the Benefits of Weight Loss. Obesity

521 Surgery:1-8. DOI: 10.1007/s11695-016-2265-2.

522 LeBlanc JG., Milani C., de Giori GS., Sesma F., van Sinderen D., Ventura M. 2013. Bacteria as

523 vitamin suppliers to their host: A gut microbiota perspective. Current Opinion in

524 Biotechnology 24:160-168. DOI: 10.1016/j.copbio.2012.08.005.

525 Ley RE., Bäckhed F., Turnbaugh P., Lozupone CA., Knight RD., Gordon JI. 2005. Obesity alters

526 gut microbial ecology. Proceedings of the National Academy of Sciences of the United

527 States of America 102:11070-5. DOI: 10.1073/pnas.0504978102. 
528 Ley R., Turnbaugh P., Klein S., Gordon J. 2006. Microbial ecology: human gut microbes

529 associated with obesity. Nature 444:1022-3. DOI: 10.1038/nature4441021a.

530 Li J V., Ashrafian H., Bueter M., Kinross J., Sands C., le Roux CW., Bloom SR., Darzi A.,

531 Athanasiou T., Marchesi JR., Nicholson JK., Holmes E. 2011. Metabolic surgery

532 profoundly influences gut microbial-host metabolic cross-talk. Gut 60:1214-23. DOI:

$533 \quad 10.1136 /$ gut.2010.234708.

534 Liou AP., Liou AP., Paziuk M., Jr JL., Machineni S. 2013. Conserved Shifts in the Gut

535 Microbiota Due to Gastric Bypass Reduce Host Weight and Adiposity. 41. DOI:

$536 \quad 10.1126 /$ scitranslmed.3005687.

537 McDonald D., Price MN., Goodrich J., Nawrocki EP., DeSantis TZ., Probst A., Andersen GL.,

538 Knight R., Hugenholtz P. 2012. An improved Greengenes taxonomy with explicit ranks for

539 ecological and evolutionary analyses of bacteria and archaea. The ISME journal 6:610-8.

$540 \quad$ DOI: $10.1038 /$ ismej.2011.139.

541 Mechanick JI., Youdim A., Jones DB., Garvey WT., Hurley DL., Mcmahon MM., Heinberg LJ.,

542 Kushner R., Adams TD., Shikora S., Dixon J., Brethauer S. 2013. Clinical Practice

543 Guidelines for the Perioperative Nutritional, Metabolic, and Nonsurgical Support of the

$544 \quad$ Bariatric Surgery. Surgery for Obesity and Related Diseases 9:159-191. DOI:

$545 \quad$ 10.1016/j.soard.2012.12.010.

546 Miquel S., Leclerc M., Martin R., Chain F., Lenoir M., Raguideau S., Hudault S., Bridonneau C.,

547 Northene T., Bowene B., Bermúdez-Humarán LG., Sokol H., Thomas M., Langella P. 2015.

548 Identification of metabolic signatures linked to anti-inflammatory effects of

549 Faecalibacterium prausnitzii. mBio 6:1-10. DOI: 10.1128/mBio.00300-15.

550 Morrison DJ., Preston T., Morrison DJ., Preston T. 2016. Formation of short chain fatty acids by 
551 the gut microbiota and their impact on human metabolism. Gut Microbes 976:1-12. DOI:

552 10.1080/19490976.2015.1134082.

553 Navas-Molina JA., Peralta-S??nchez JM., Gonz??lez A., McMurdie PJ., V??zquez-Baeza Y., Xu 554 Z., Ursell LK., Lauber C., Zhou H., Song SJ., Huntley J., Ackermann GL., Berg-Lyons D., 555 Holmes S., Caporaso JG., Knight R. 2013. Advancing our understanding of the human 556 microbiome using QIIME. Methods in Enzymology 531:371-444. DOI: 10.1016/B978-012-407863-5.00019-8.

Palleja A., Kashani A., Allin KH., Nielsen T., Zhang C., Li Y., Brach T., Liang S., Feng Q., Jørgensen NB., Bojsen-møller KN., Dirksen C., Burgdorf KS., Holst JJ., Madsbad S., Wang J., Pedersen O., Hansen T., Arumugam M. 2016. Roux-en-Y gastric bypass surgery of morbidly obese patients induces swift and persistent changes of the individual gut microbiota. Genome Medicine:1-13. DOI: 10.1186/s13073-016-0312-1.

Qin J., Balzola F., Bernstein C., Ho GT., Lees C., Bork P., Dusko E., Wang J. 2010. A human gut microbial gene catalogue established by metagenomic sequencing: Commentary. Inflammatory Bowel Disease Monitor 11:28. DOI: 10.1038/nature08821.

R Core Team. 2013. R Core Team. $R$ : A language and environment for statistical computing. $R$ Foundation for Statistical Computing, Vienna, Austria.:ISBN 3-900051-07-0, URL http://www.R-project.org/.

Rinttilä T., Kassinen A., Malinen E., Krogius L., Palva A. 2004. Development of an extensive set of $16 \mathrm{~S}$ rDNA-targeted primers for quantification of pathogenic and indigenous bacteria in faecal samples by real-time PCR. Journal of Applied Microbiology 97:1166-1177. DOI: 10.1111/j.1365-2672.2004.02409.x.

573 Schauer PR., Bhatt DL., Kirwan JP., Wolski K., Brethauer SA., Navaneethan SD., Aminian A., 
Pothier CE., Kim ESH., Nissen SE., Kashyap SR. 2014. Bariatric Surgery versus Intensive Medical Therapy for Diabetes — 3-Year Outcomes. New England Journal of Medicine 370:2002-2013. DOI: 10.1056/NEJMoa1401329.

Schneeberger M., Everard A., Gómez-Valadés AG., Matamoros S., Ramírez S., Delzenne NM., Gomis R., Claret M., Cani PD. 2015. Akkermansia muciniphila inversely correlates with the onset of inflammation, altered adipose tissue metabolism and metabolic disorders during obesity in mice. Scientific reports 5:16643. DOI: 10.1038/srep16643.

Sekirov I., Russell SL., Antunes LCM., Finlay BB. 2010. Gut Microbiota in Health and Disease. Physiological Reviews 90:859-904. DOI: 10.1152/physrev.00045.2009.

Shao Y., Ding R., Xu B., Hua R., Shen Q., He K., Yao Q. 2016. Alterations of Gut Microbiota After Roux-en-Y Gastric Bypass and Sleeve Gastrectomy in Sprague-Dawley Rats. Obesity Surgery. DOI: 10.1007/s11695-016-2297-7.

Sjöström L. 2008. Bariatric surgery and reduction in morbidity and mortality: experiences from

Sjöström L., Narbro K., Sjöström CD., Karason K., Larsson B., Wedel H., Lystig T., Sullivan

590 M., Bouchard C., Carlsson B., Bengtsson C., Dahlgren S., Gummesson A., Jacobson P., 591 Karlsson J., Lindroos A-K., Lönroth H., Näslund I., Olbers T., Stenlöf K., Torgerson J., 592 Agren G., Carlsson LMS., Swedish Obese Subjects Study. 2007. Effects of bariatric surgery

595 Tennant B., Malm OJ., Horowitz RE., Levenson SM. 1968. Response of germfree, conventional, 596 conventionalized and E. coli monocontaminated mice to starvation. The Journal of nutrition 
94:151-160.

598 Tice JA., Karliner L., Walsh J., Petersen AJ., Feldman MD. 2008. Gastric Banding or Bypass? A 599 Systematic Review Comparing the Two Most Popular Bariatric Procedures. American $600 \quad$ Journal of Medicine 121:885-893. DOI: 10.1016/j.amjmed.2008.05.036.

601 Todesco T., Rao a V., Bosello O., Jenkins DJ. 1991. Propionate lowers blood glucose and alters 602 lipid metabolism in healthy subjects. The American journal of clinical nutrition 54:860-5. 603 Tran DD., Nwokeabia ID., Purnell S., Zafar SN., Ortega G., Hughes K., Fullum TM. 2016. 604 Revision of Roux-En-Y Gastric Bypass for Weight Regain: a Systematic Review of 605 Techniques and Outcomes. Obesity Surgery. DOI: 10.1007/s11695-016-2201-5.

606 Tremaroli V., Karlsson F., Werling M., Stahlman M., Kovatcheva-Datchary P., Olbers T., 607 Fandriks L., Le Roux CW., Nielsen J., Backhed F. 2015. Roux-en-Y Gastric Bypass and 608 Vertical Banded Gastroplasty Induce Long-Term Changes on the Human Gut Microbiome 609 Contributing to Fat Mass Regulation. Cell Metabolism 22:228-238. DOI:

$610 \quad$ 10.1016/j.cmet.2015.07.009.

611 Turnbaugh PJ., Ley RE., Mahowald M a., Magrini V., Mardis ER., Gordon JI. 2006. An obesity612 associated gut microbiome with increased capacity for energy harvest. Nature 444:1027-31. 613 DOI: $10.1038 /$ nature 05414.

614 Walters WA., Xu Z., Knight R. 2014. Meta-analyses of human gut microbes associated with 615 obesity and IBD. FEBS Letters 588:4223-4233. DOI: 10.1016/j.febslet.2014.09.039.

616 World Health Organization. 2016.No Title. Available at

617 http://www.who.int/mediacentre/factsheets/fs311/en/(accessed June 1, 2016).

618 Yatsunenko T., Rey FE., Manary MJ., Trehan I., Dominguez-Bello MG., Contreras M., Magris

619 M., Hidalgo G., Baldassano RN., Anokhin AP., Heath AC., Warner B., Reeder J., 
620 Kuczynski J., Caporaso JG., Lozupone CA., Lauber C., Clemente JC., Knights D., Knight

621 R., Gordon JI. 2012. Human gut microbiome viewed across age and geography. Nature 622 486:222-227. DOI: 10.1038/nature11053.

623 Zhang H., DiBaise JK., Zuccolo A., Kudrna D., Braidotti M., Yu Y., Parameswaran P., Crowell

624 MD., Wing R., Rittmann BE., Krajmalnik-Brown R. 2009. Human gut microbiota in obesity 625 and after gastric bypass. Proceedings of the National Academy of Sciences of the United

$626 \quad$ States of America 106:2365-70. DOI: 10.1073/pnas.0812600106. 


\section{Figure 1}

Rarefaction curves and Principal Component Analysis of the gut microbiota composition of the subjects of the study, obtained by $16 \mathrm{~S}$ rRNA sequencing and QIIME.

A: rarefaction curves for all samples sequenced, indicating the number of OTUs observed with different sequencing depths; $B, C$ and D: 2D-PCoA analysis of gut microbiota composition at time 0 (red squares) compared to 6 months after treatment (blue circles), for medical treatment subjects (MT), Sleeve Gastrectomy (SG) and Roux-en-Y Gastric Bypass (RYGB) groups. 

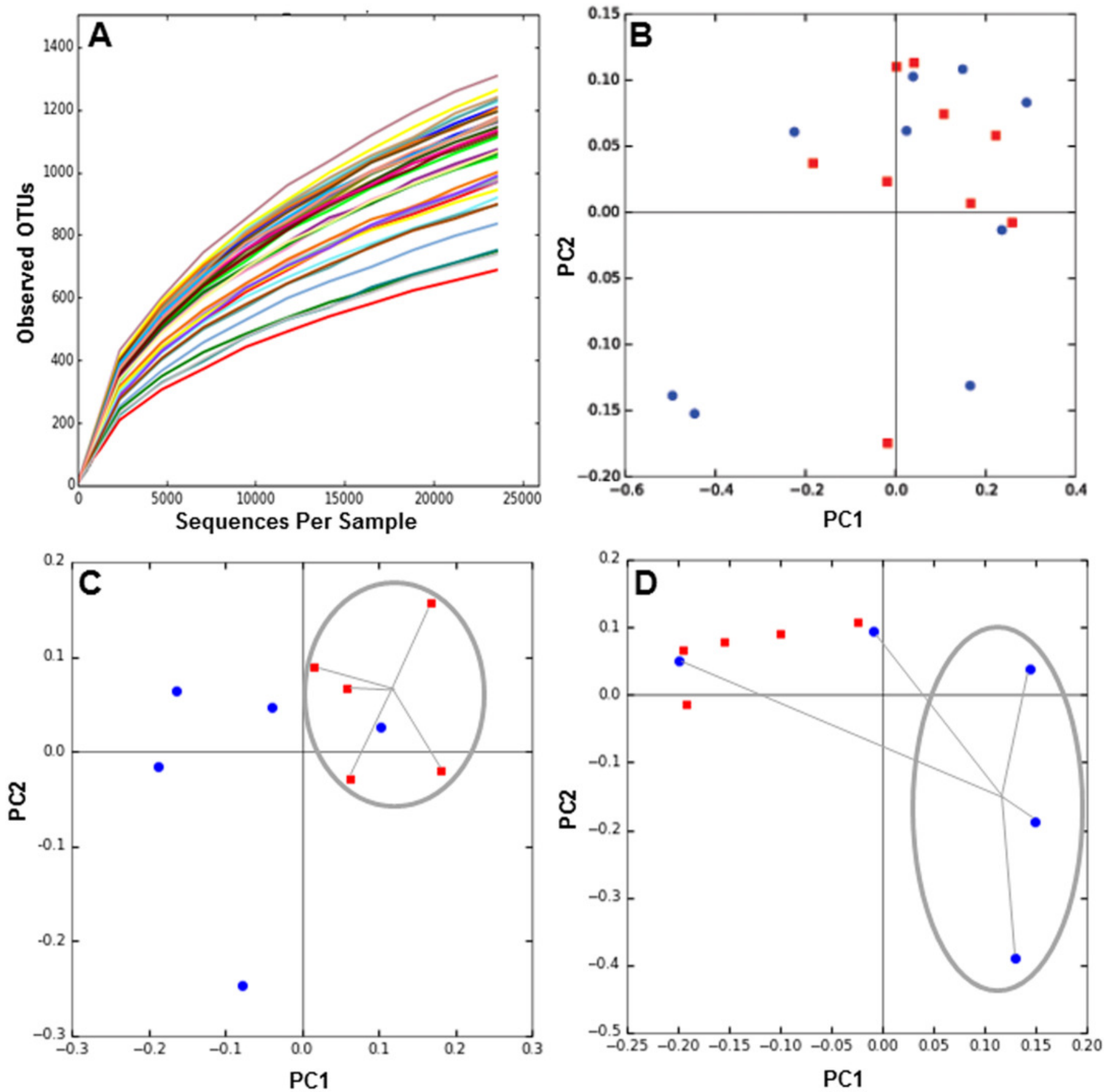


\section{Figure 2}

Relative abundance of major bacterial phyla in the gut microbiota of the three groups of the study, before and after each treatment.

A: average relative abundance of four representative phyla (indicated in the upper part), at time 0 and 6 months, in medical treatment (MT), Sleeve Gastrectomy (SG) or Roux-en-Y Gastric Bypass (RYGB) groups; B, C and D: changes in the abundance of each phylum after/before each treatment. The phyla are represented from left to right side as Act (Actinobacteria), Bac (Bacteroidetes), Fir (Firmicutes), Pro (Proteobacteria). Values were expressed as fold change and $\log (2)$ normalized; E: Bacteroidetes/Firmicutes ratio at time 0 (red) and 6 months after treatment (light blue) for Medical Treatment (MT), Roux-en-Y gastric bypass (GB) and Sleeve Gastrectomy (SG). Asterisk indicates significant fold change differences ( $p$-value $<0,05$ ).
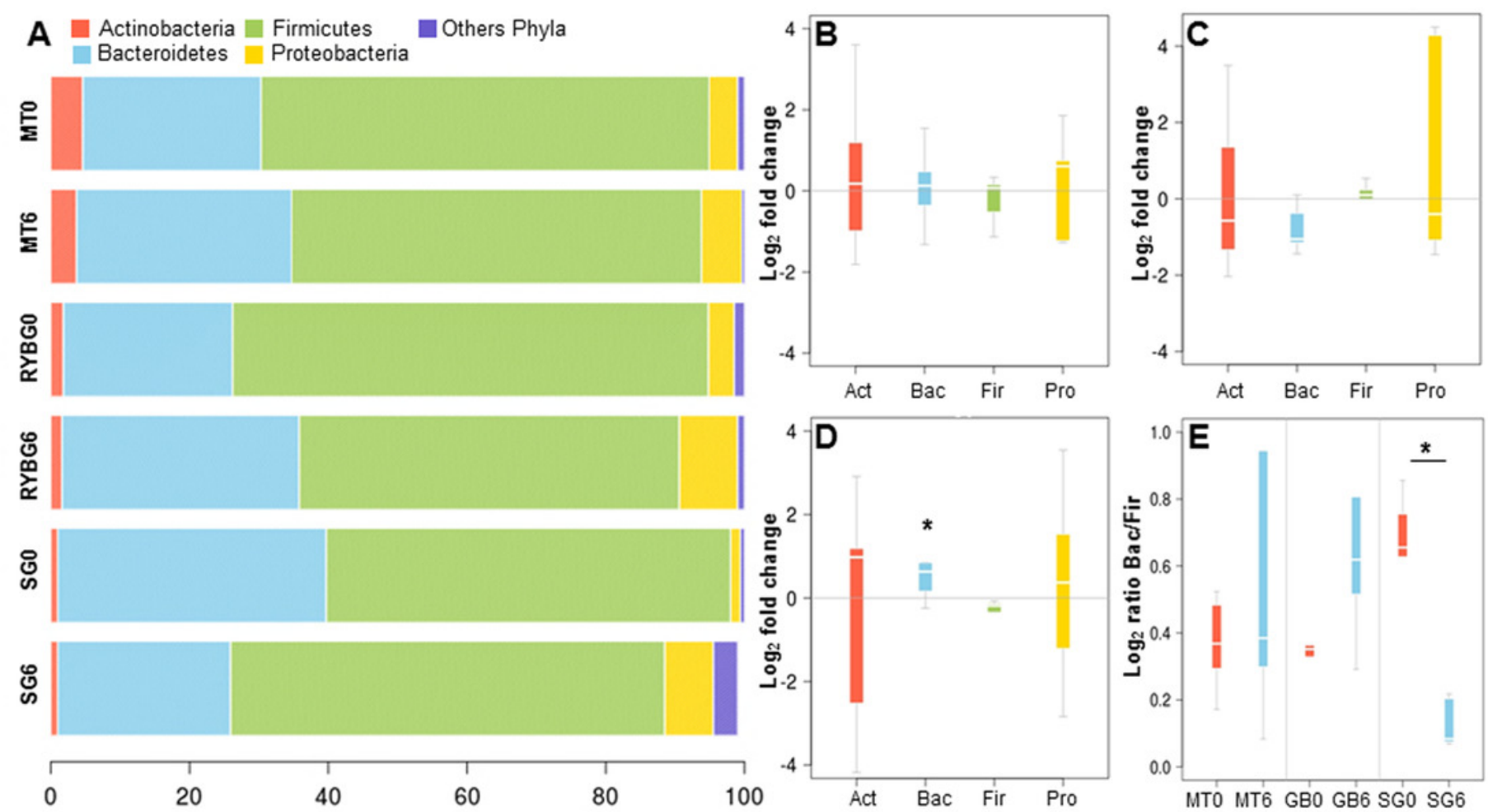


\section{Figure 3}

Changes in major phyla in the gut microbiota after each obesity treatment measured by qPCR.

A, B and C: ratio of the abundance of each phylum after/before each treatment. The changes are represented from left to right side as Act (Actinobacteria), Bac (Bacteroidetes), Fir (Firmicutes), Ent (Enterobacteriales). Values were expressed as fold change and log normalized. D: Ratio of Bacteroidetes/Firmicutes at time 0 (black) and 6 months after treatment (grey). Asterisk indicates significant fold change differences ( $p$-value $<0.05$ ).
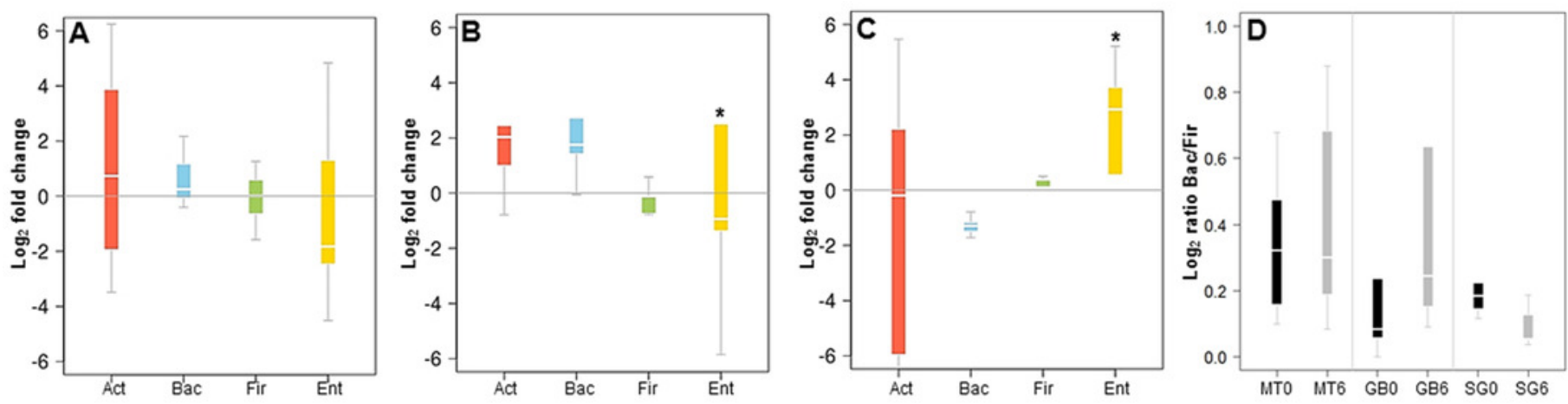


\section{Figure 4}

Gut microbiota comparison across subjects before and after the obesity treatment.

Heatmap of pairwise Spearman Rank correlations for gut microbiota abundance, with other subjects in the study. A: Pairwise correlations for all subjects before each intervention (Medical Treatment (MT), Roux-en-Y Gastric Bypass (GB) and Sleeve Gastrectomy (SG); numbers indicate subjects); B: Pairwise correlations for all subjects six months after each treatment. Legend in the bottom indicates the scale of correlation across different gut microbiota compositions.

A

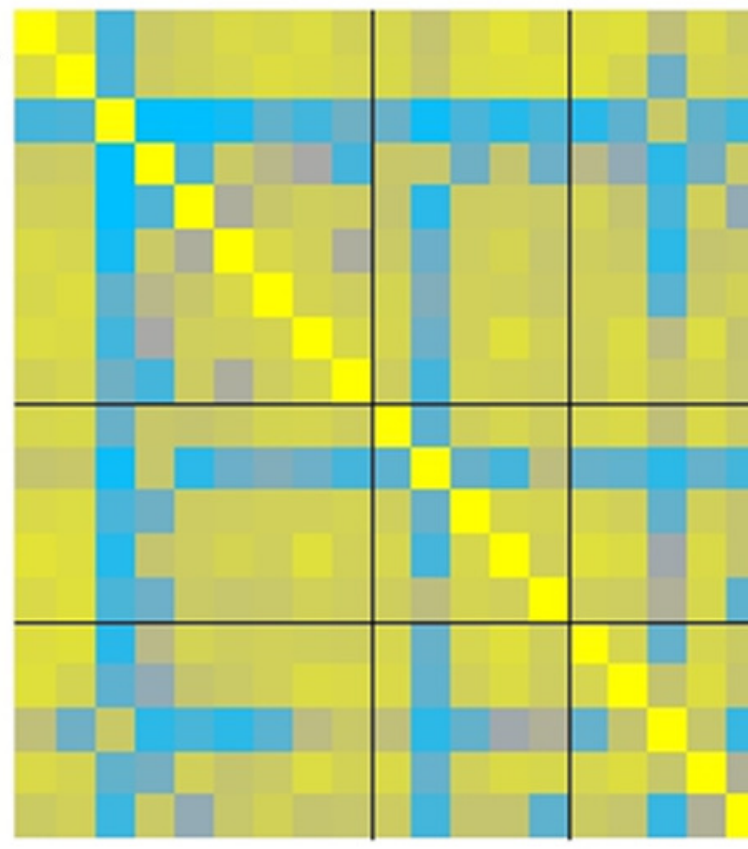

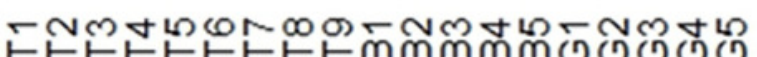

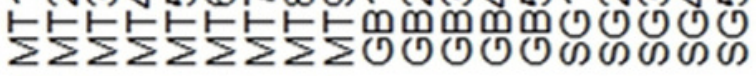



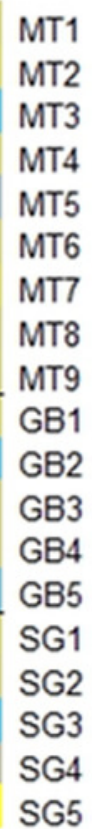

SG5

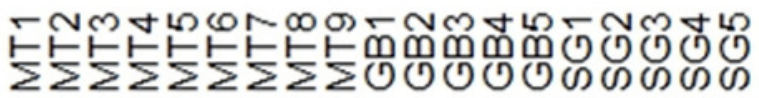




\section{Figure 5}

Figure 5: Correlations between clinical data change and gut microbiota variation.

Heatmap of pairwise Spearman Rank correlation analysis of microbiome changes with changes in clinical markers, considering data after and before the treatment. Data corresponds to subjects on Medical Treatment (A), Roux-en-Y gastric bypass (B) and Sleeve Gastrectomy (C). The phyla are represented from left to right side as Act (Actinobacteria), Fir (Firmicutes), Bac (Bacteroidetes) and Pro (Proteobacteria). Blue denotes a negative correlation while yellow indicates positive correlations. The asterisk denotes significant correlation values ( $p$-value $<0.05)$.
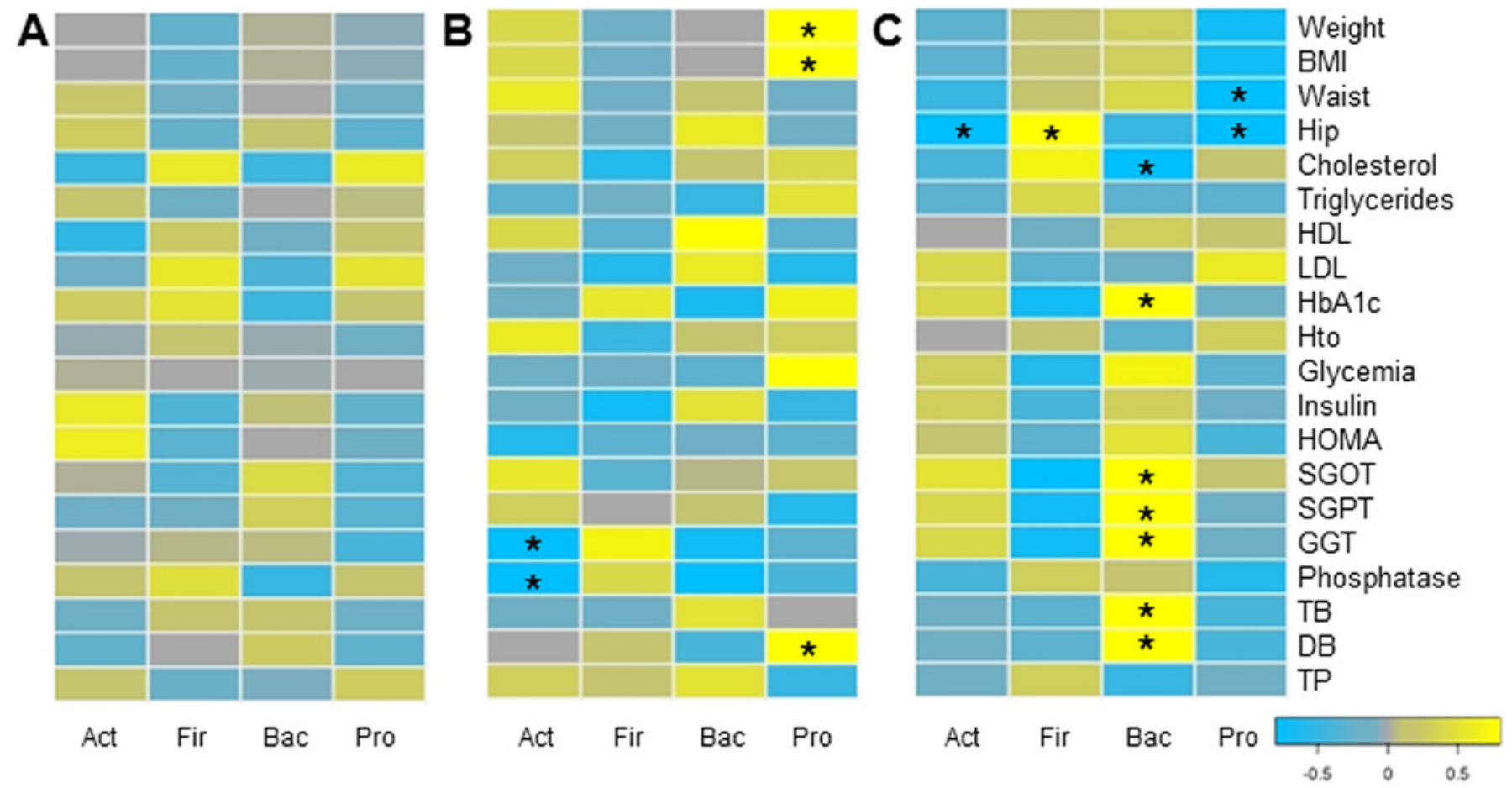


\section{Table $\mathbf{1}$ (on next page)}

Clinical and anthropometric parameters before ( 0 month) and after treatment (6 months).

Significant p-values (Mann-Whitney test) are denoted by bold numbers. MT: Medical Treatment, RYGB: Roux-en-Y Gastric Bypass, SG: Sleeve Gastrectomy 
1 Table 1: Clinical and anthropometric parameters before ( 0 month $)$ and after each obesity treatment

2 (6 months). Significant p-values (Mann-Whitney test) are denoted by bold numbers. MT: Medical

3 Treatment, RYGB: Roux-en-Y Gastric Bypass, SG: Sleeve Gastrectomy

4

\begin{tabular}{|c|c|c|c|c|c|c|c|c|c|}
\hline Treatment (time) & $\begin{array}{c}\text { MT } \\
(0 \text { months }) \\
\end{array}$ & $\begin{array}{c}\text { MT } \\
\text { (6 months) } \\
\end{array}$ & $\mathrm{p}$-value & $\begin{array}{c}\text { RYGB } \\
(0 \text { months }) \\
\end{array}$ & $\begin{array}{c}\text { RYGB } \\
\text { (6 months) }\end{array}$ & $\mathrm{p}$-value & $\begin{array}{c}\text { SG } \\
(0 \text { months })\end{array}$ & $\begin{array}{c}\text { SG } \\
\text { (6 months) }\end{array}$ & p-value \\
\hline \multicolumn{10}{|c|}{ Anthropometric data } \\
\hline Weight (kg) & $102.3 \pm 23$ & $99.5 \pm 23.7$ & 0.479 & $100.1 \pm 11.6$ & $72.1 \pm 11.2$ & 0.008 & $88.9 \pm 7.5$ & $62.7 \pm 4.2$ & 0.008 \\
\hline BMI $(\mathrm{kg} / \mathrm{m} 2)$ & $38.9 \pm 5.8$ & $37.8 \pm 6.7$ & 0.86 & $37.1 \pm 2.8$ & $26.7 \pm 3.1$ & 0.012 & $35.2 \pm 2.4$ & $24.9 \pm 2.9$ & 0.012 \\
\hline $\begin{array}{l}\text { Waist circumference } \\
(\mathrm{cm})\end{array}$ & $107.8 \pm 13.4$ & $99.3 \pm 16.6$ & 0.269 & $102.6 \pm 12.5$ & $76.4 \pm 7.1$ & 0.021 & $95.2 \pm 10.5$ & $73.6 \pm 8$ & 0.015 \\
\hline Hip perimeter $(\mathrm{cm})$ & $116.0 \pm 10.4$ & $111.2 \pm 14.8$ & 0.374 & $116.4 \pm 7.8$ & $97.2 \pm 5.4$ & 0.016 & $105.3 \pm 4.5$ & $91.0 \pm 4.1$ & 0.036 \\
\hline \multicolumn{10}{|c|}{ Lipid metabolism } \\
\hline Cholesterol (mg/dL) & $185.6 \pm 35.4$ & $178.0 \pm 15.5$ & 0.825 & $216.8 \pm 88.5$ & $148.6 \pm 39.8$ & 0.095 & $174.2 \pm 21.1$ & $171.4 \pm 15.4$ & 0.841 \\
\hline Triglycerides $(\mathrm{mg} / \mathrm{dL})$ & $109.0 \pm 28.8$ & $109.4 \pm 30.8$ & 0.965 & $349.0 \pm 443.5$ & $119.6 \pm 69.9$ & 0.151 & $151.6 \pm 87.3$ & $205.6 \pm 246.3$ & 0.841 \\
\hline $\mathrm{HDL}(\mathrm{mg} / \mathrm{dL})$ & $52.0 \pm 12.9$ & $56.1 \pm 122$ & 0.401 & $43.4 \pm 6.4$ & $46.6 \pm 10.6$ & 0.753 & $44.4 \pm 13.5$ & $50.0 \pm 17$ & 0.599 \\
\hline LDL (mg/dL) & $111.8 \pm 32.2$ & $100.1 \pm 14.8$ & 0.48 & $103.8 \pm 19$ & $78.0 \pm 18$ & 0.095 & $99.0 \pm 15.8$ & $80.2 \pm 36.2$ & 0.6 \\
\hline \multicolumn{10}{|c|}{ Glucose metabolism } \\
\hline Glycemia (mg/dL) & $95.6 \pm 11.7$ & $90.4 \pm 13.2$ & 0.426 & $93.4 \pm 14.2$ & $78.2 \pm 4.4$ & 0.032 & $89.6 \pm 19.7$ & $75.4 \pm 2.4$ & 0.343 \\
\hline Insulin (mcU/dL) & $39.6 \pm 25.4$ & $26.1 \pm 16.2$ & 0.136 & $16.7 \pm 7.9$ & $5.9 \pm 3$ & 0.008 & $14.3 \pm 5.3$ & $6.4 \pm 2.8$ & 0.036 \\
\hline HOMA & $9.4 \pm 6.2$ & $6.1 \pm 4.4$ & 0.102 & $3.4 \pm 1.6$ & $1.2 \pm 0.7$ & 0.008 & $3.0 \pm 1.4$ & $1.2 \pm 0.5$ & 0.032 \\
\hline $\mathrm{HbA} 1 \mathrm{c}(\%)$ & $5.9 \pm 0.5$ & $5.8 \pm 0.5$ & 0.894 & $5.5 \pm 0.1$ & $5.5 \pm 0.2$ & 0.589 & $5.5 \pm 0.5$ & $5.6 \pm 0.5$ & 0.916 \\
\hline \multicolumn{10}{|c|}{ Liver function } \\
\hline SGOT (UI/L) & $35.1 \pm 18$ & $31.3 \pm 19.5$ & 0.659 & $18.6 \pm 5$ & $16.4 \pm 1.9$ & 0.67 & $29.0 \pm 21.7$ & $15.6 \pm 3$ & 0.205 \\
\hline SGPT (UI/L) & $57.2 \pm 34.9$ & $37.2 \pm 23.7$ & 0.216 & $17.6 \pm 5.9$ & $13.2 \pm 3.6$ & 0.243 & $28.6 \pm 14.4$ & $15.0 \pm 4.8$ & 0.206 \\
\hline GGT (UI/L) & $48.2 \pm 40$ & $36.4 \pm 39$ & 0.17 & $17.0 \pm 1.9$ & $8.6 \pm 1.7$ & 0.011 & $23.2 \pm 14.1$ & $11.0 \pm 1.6$ & 0.016 \\
\hline Phosphatase A (UI/L) & $82.8 \pm 16.8$ & $78.1 \pm 18.9$ & 0.895 & $55.0 \pm 34.5$ & $86.0 \pm 22.7$ & 0.222 & $85.2 \pm 22.1$ & $78.0 \pm 10.5$ & 0.548 \\
\hline $\begin{array}{l}\text { Total Bilirrubin } \\
(\mathrm{mg} / \mathrm{dL})\end{array}$ & $0.4 \pm 0.2$ & $0.5 \pm 0.2$ & 0.387 & $0.3 \pm 0.1$ & $0.4 \pm 0.2$ & 0.548 & $14.6 \pm 31.5$ & $0.4 \pm 0.3$ & 0.548 \\
\hline $\begin{array}{l}\text { Direct Bilirrubin } \\
(\mathrm{mg} / \mathrm{dL})\end{array}$ & $0.2 \pm 0.06$ & $0.2 \pm 0.1$ & 0.142 & $0.1 \pm 0.03$ & $0.2 \pm 0.1$ & 0.074 & $0.2 \pm 0.1$ & $0.2 \pm 0.1$ & 0.675 \\
\hline Total Protein $(\%)$ & $97.1 \pm 15$ & $104.8 \pm 14.4$ & 0.401 & $98.4 \pm 4.7$ & $91.4 \pm 11.6$ & 0.248 & $97.0 \pm 5.1$ & $101.2 \pm 11.2$ & 0.527 \\
\hline \multicolumn{10}{|c|}{ Plasmatic data } \\
\hline Hto & $43.0 \pm 3$ & $42.3 \pm 3.3$ & 0.596 & $39.6 \pm 3.9$ & $35.9 \pm 4.9$ & 0.222 & $41.0 \pm 2$ & $38.3 \pm 3.2$ & 0.222 \\
\hline
\end{tabular}




\section{Table 2 (on next page)}

Top ten OTUs (genera or species), with the highest fold change between 0 and 6 months after each treatment.

Abundance values are expressed as the average of each species abundance in all patients on each group and expressed as percentage. Fold change is the ratio 6 to 0 months and values are $\log (2)$ normalized. 
